\title{
Hepatotoxicity from green tea: a review of the literature and two unpublished cases
}

\author{
Gabriela Mazzanti • Francesca Menniti-Ippolito • \\ Paola Angela Moro • Federica Cassetti • \\ Roberto Raschetti • Carmela Santuccio • \\ Sabina Mastrangelo
}

Received: 22 October 2008 / Accepted: 30 December 2008 / Published online: 6 February 2009

(C) Springer-Verlag 2009

\begin{abstract}
Purpose To review the current literature on suspected green tea-related hepatic reactions and to describe two new cases reported within the framework of the Italian surveillance system of natural health products.

Results A literature search of publication between 1999 and October 2008 retrieved 34 cases of hepatitis. Histological examination of the liver revealed inflammatory reactions, cholestasis, occasional steatosis, and necrosis. A positive dechallenge was reported in 29 cases. There was one reported death. A positive rechallenge occurred in seven cases $(20 \%)$. In the two new cases, the causality assessment was judged as "possible" according to the RUCAM score.

Conclusions Our analysis of the published case reports suggests a causal association between green tea and liver damage. The hepatotoxicity is probably due to (-)-epigallocatechin gallate or its metabolites which, under particular conditions related to the patient's metabolism, can induce
\end{abstract}

G. Mazzanti $(\bowtie) \cdot S$. Mastrangelo

Department of Physiology and Pharmacology, Sapienza,

University of Rome,

P.le Aldo Moro, 5,

00185 Rome, Italy

e-mail: gabriela.mazzanti@uniroma1.it

F. Menniti-Ippolito $\cdot$ R. Raschetti

National Center for Epidemiology, National Institute of Health, Rome, Italy

P. A. Moro · F. Cassetti

Poison Control Center, Niguarda Ca' Granda Hospital,

Milan, Italy

C. Santuccio

Pharmacovigilance Unit, Italian Medicines Agency,

Rome, Italy oxidative stress in the liver. In a few cases, toxicity related to concomitant medications could also be involved.

Keywords Green tea · Camellia sinensis · Catechins . Epigallocatechin gallate $\cdot$ Hepatotoxicity .

Herbal supplements

\section{Introduction}

The consumption of tea originated in China and Southeast Asia thousands of years ago and was thereafter introduced progressively all around the world. Historically, green tea has been lauded for various beneficial health effects, and more recently its biological activities have been investigated. Tea is obtained from the leaves of Camellia sinensis (L.) Kuntze (Fam. Theaceae). Its composition varies with climate, season, horticultural practices, variety and age of the plant, and manner in which the leaves have been processed. There are several commercial kinds of tea, of which the main ones are green, black, and oolong tea. To obtain green tea, fresh leaves are stabilized by dry heating or steaming to inactivate the enzymes, then rolled, dried rapidly, and more or less roasted. To obtain black tea, leaves are allowed to wilt for about $20 \mathrm{~h}$, rolled, fermented in a humid atmosphere, then dried with hot air; black tea represents $80 \%$ of the world market. Oolong tea is only partially fermented [1].

The main chemical components of unfermented tea are polyphenols (up to $20 \%$ and more of the dry weight), of which the main ones are catechins, mainly (-)-epigallocatechin gallate (EGCG, 5-12\%) and (-)-epicatechin gallate (ECG, $1-5 \%$ ) [1]. Tea is also a good source of methylxanthines, primarily in the form of caffeine $(2-5 \%)$, with smaller quantities of theobromine and theophylline. Fermentation 
induces changes in the composition; in addition to the development of the aroma, following the formation of volatile products, polyphenols undergo oxidation.

Some studies have shown that green tea consumption is associated with a reduced risk of cardiovascular diseases, degenerative diseases, and cancer [2-4]. The potential health benefits associated with tea consumption have been partially attributed to the antioxidative properties of polyphenols, particularly to catechins, among which EGCG is the most effective. Green tea seems to also have antidiabetic and anti-obesity properties [5]. On the basis of its potential anti-obesity effect, green tea has been marketed during recent years as a herbal supplement for the control of body weight. Unfortunately, some reports of adverse effects, mainly hepatitis, associated to the consumption of green tea preparations have been published. In April 2003, the manufacturer of Exolise (Arkopharma, Carros, France), a green tea extract containing high EGCG levels and marketed as a weight loss supplement, withdrew this product from the market owing to 13 cases of liver damage due to its consumption [www.afssaps.sante.fr]. The same product was also removed from the Spanish market because of other hepatotoxicity cases. Since then, much attention has been given to the possible hepatotoxic effects of green tea. Despite the withdrawal of Exolise from the market, other green tea-based herbal supplements have been marketed, and reports of hepatotoxicity from green tea are increasing.

In this paper, we present a review of the current literature on suspected hepatotoxicity due to the consumption of green tea along with two new cases reported within the surveillance system of natural health products active in Italy [6].

Seventeen cases of hepatotoxicity related to Tealine [7-9] were not included in our review. The consumption of Tealine, a body weight supplement containing Teucrium chamaedrys (germander) and green tea powdered leaves, was reported to be hepatotoxic in the early 1990s, but the adverse reactions were subsequently attributed to the germander.

\section{Methods}

In order to collect literature reports on green tea hepatotoxicity, we carried out a systematic search of case reports on the Medline database. The references of all retrieved papers were then carefully investigated. The keywords for liver damage were: hepatotoxicity, liver injury, hepatitis, hepatic failure, hepatic necrosis, hepatic fibrosis, cirrhosis, cholestasis, and veno-occlusive disease. Each term was matched with Camellia sinensis, green tea, polyphenols, catechins, EGCG, epigallocatechin gallate, EGC, and other broad keywords, such as herbal medicine, alternative medicine, plant extracts, dietary supplements, herbal drug, and medicinal plants. No temporal limits were given to the search; articles in English, French, Italian, Spanish, and German were considered.

Two new cases were collected within the Italian surveillance system of suspected adverse reactions to natural health products. The system was set up by the Italian National Institute of Health (Istituto Superiore di Sanità) in April 2002 to identify and compile suspected adverse reactions to any kind of natural health product (medicinal plants, dietary supplements, among others) that are not included in the National pharmacovigilance system.

The causality assessment on the two new cases was performed according to the RUCAM method [10]. This method is considered to be the most appropriate approach for evaluating the role of a substance in the development of adverse reactions to drugs; it has been standardized for drug-induced liver injuries.

\section{Results}

Thirty-four cases of hepatitis following the consumption of preparations containing green tea were retrieved from Medline between 1999 and October 2008 [11-35] (Table 1). Six cases were men (27-45 years old) and 28 women (1969 years old). In 15 patients, herbal preparations containing only green tea (nine of the 15 subjects took Exolise) were used; in the others, multicomponent preparations had been ingested. All supplements were used as weight loss products.

Laboratory tests showed high values of transaminases (values up to 140 -fold higher than normal), alkaline phosphatase levels that varied from normal to 8.3-fold higher than the normal values, gamma glutamyl transpeptidase levels up up to $394 \mathrm{U} / \mathrm{L}$, and bilirubin levels up to 25 -fold above the normal values. According to the RUCAM scale, liver injury in the 32 assessable cases was classified as hepatocellular $(62.50 \%)$, cholestatic $(18.75 \%)$, or mixed (18.75\%) (Table 1) [10].

The time of onset of the reaction varied between 4 days and 4 years; however, onset was $\leq 4$ weeks in $25 \%$ of the cases and $\leq 3$ months in $70 \%$ (Table 1). The histological examination, when performed, showed inflammatory reactions, cholestasis, sometimes steatosis, and necrosis (Table 1). Serum analysis confirmed negative viral serology for active hepatitis $\mathrm{A}, \mathrm{B}$, and $\mathrm{C}$ in all patients. An autoimmune reaction was also generally excluded by the measurement of nonorgan specific autoantibody serum levels.

Risk factors related to the age were present only in five of 34 subjects. Alcoholism was generally excluded. In 15 cases, the consumption of other medications (both synthetic and herbal drugs) was reported; in seven cases, no other medication was declared. 


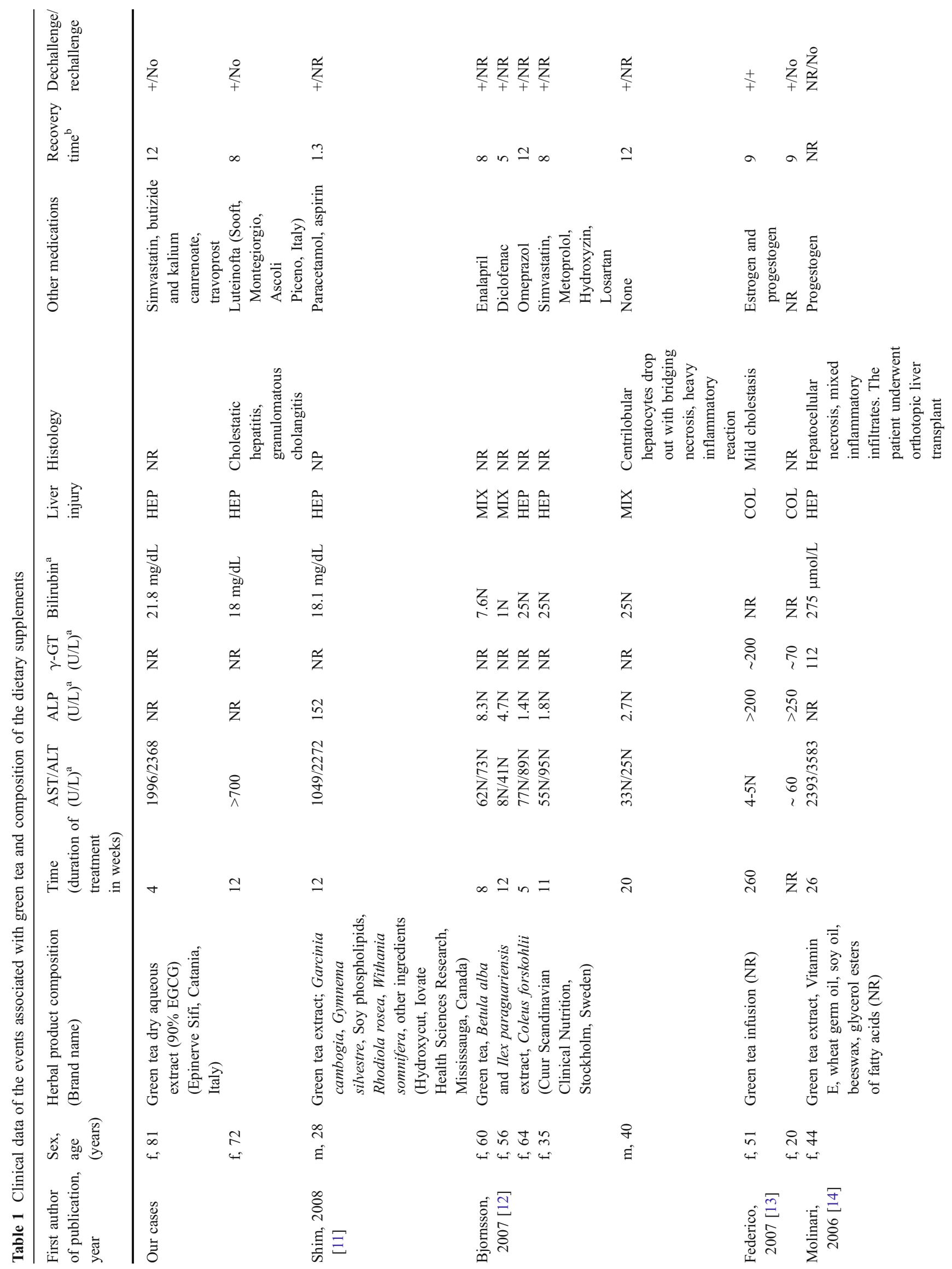




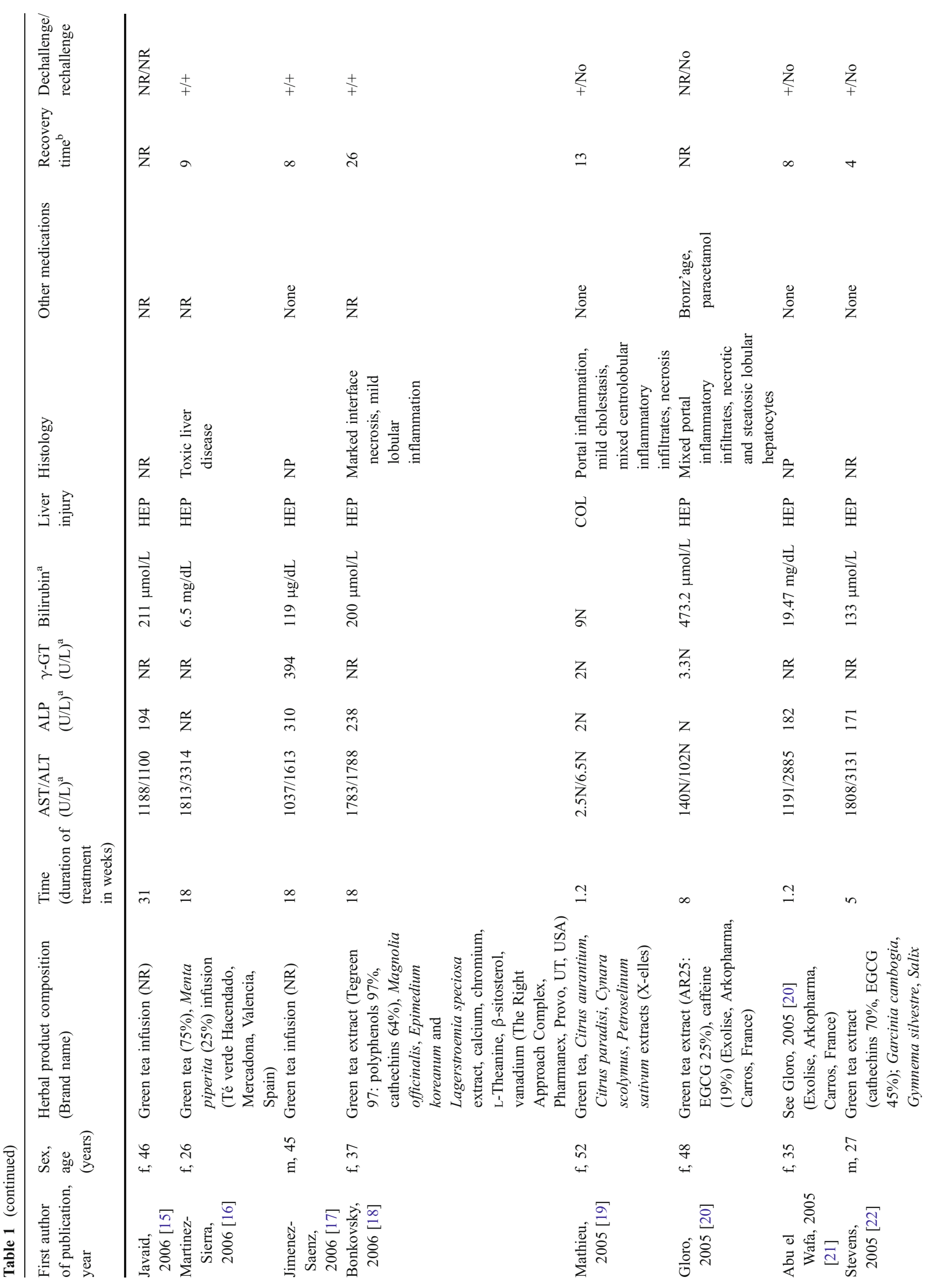



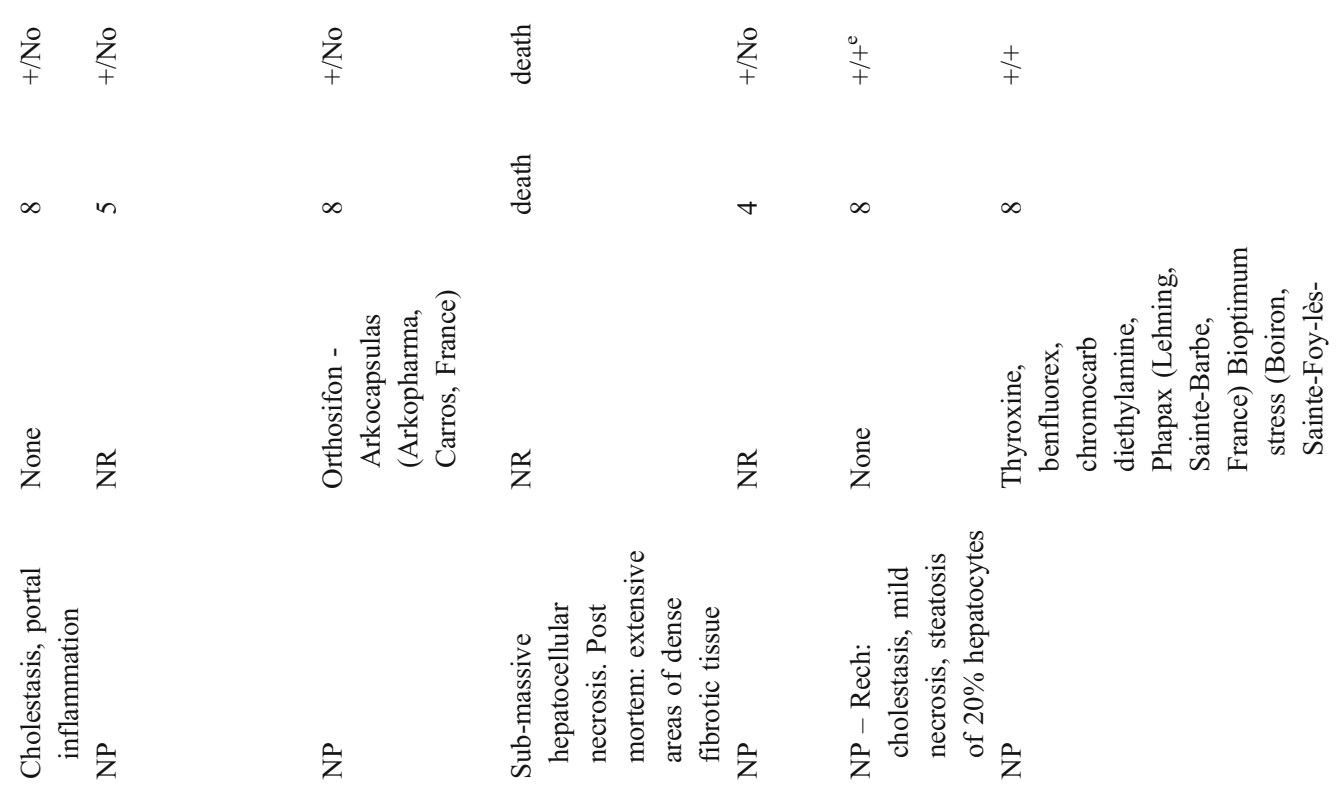

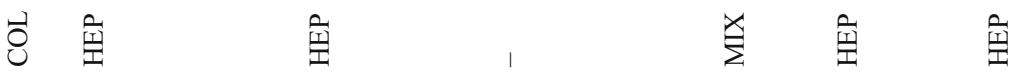

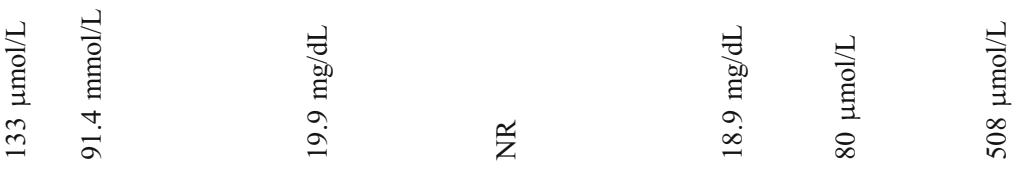

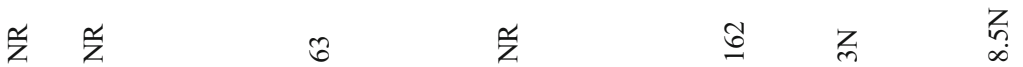

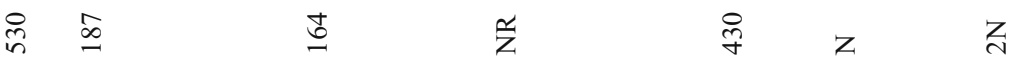

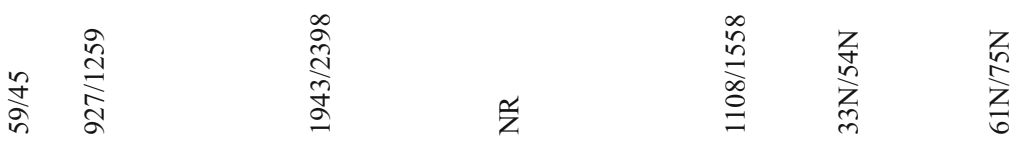

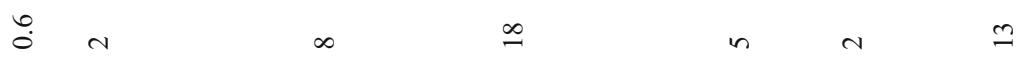
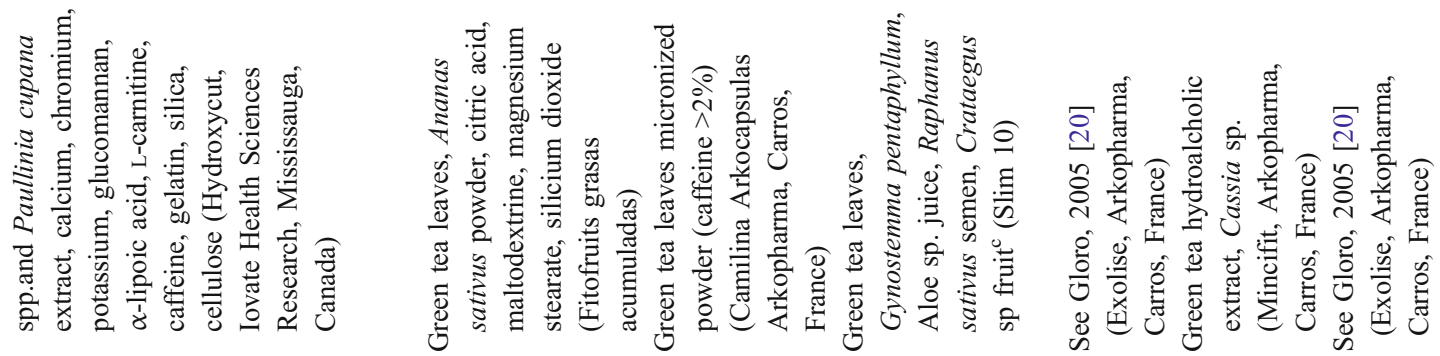
$\stackrel{n}{\approx} \quad n$
$\stackrel{2}{4}$
g
$\stackrel{0}{3} \stackrel{0}{9}$
鼠

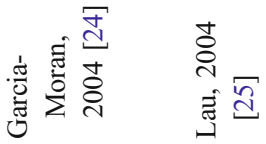

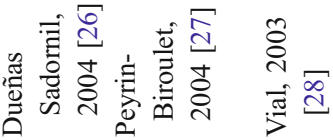




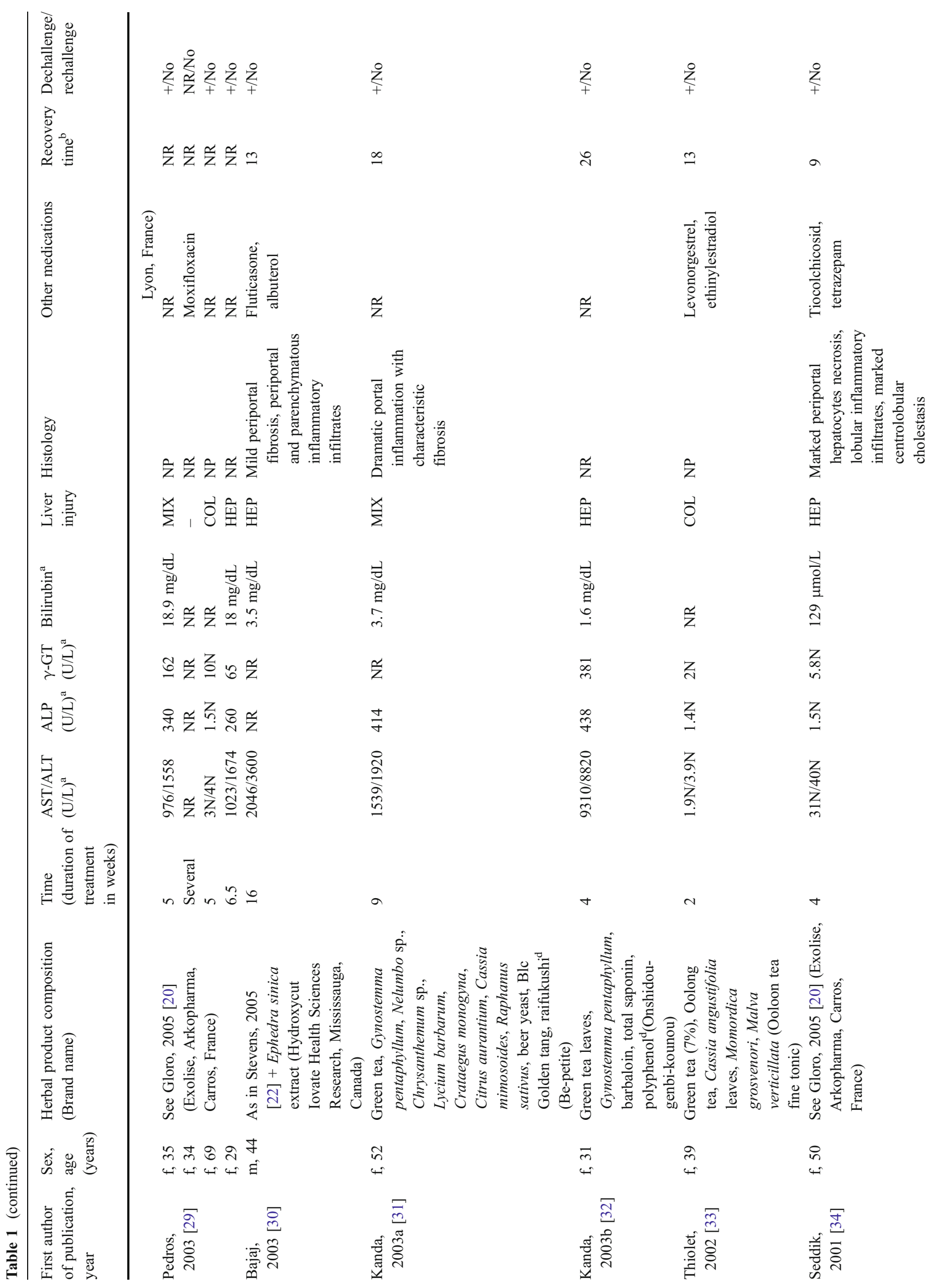




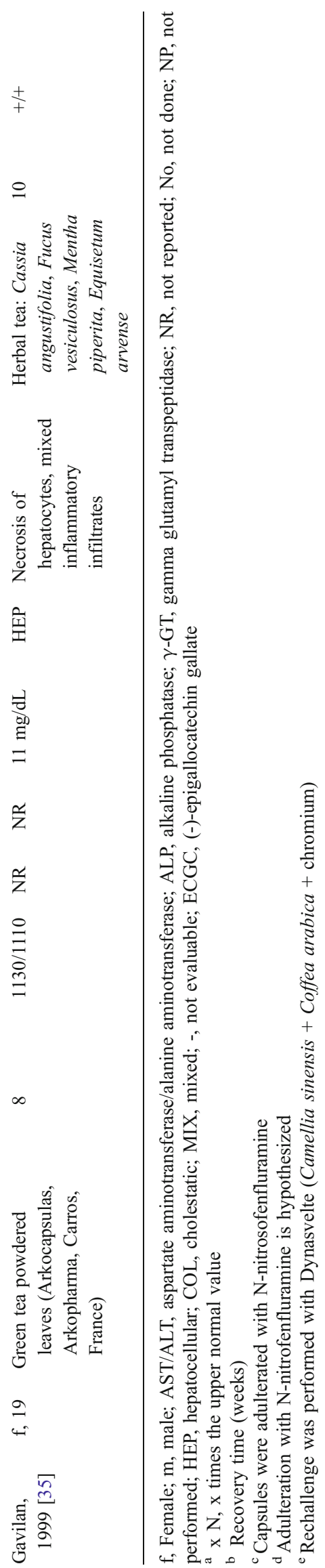

In 29 cases, the reaction ameliorated when consumption of the herbal product ceased (positive dechallenge), in four cases the dechallenge was not reported. The recovery generally required from 4 to 13 weeks; one death was also registered. A positive rechallenge occurred in seven cases $[13,16-18,27,28,35]$.

In the following sections we describe two new cases reported within the Italian surveillance system of natural health products.

Case 1

An 81-year-old Italian woman was admitted to the hospital for severe asthenia, jaundice, pale feces, dark urine, nausea, and vomiting. A toxic acute hepatitis was diagnosed. Results from the abdominal ultrasonography excluded alterations of the hepatic parenchyma, intra- and extrahepatic bile-duct dilatation, and pancreatic alterations. The results of the laboratory tests were: alanine aminotransferase (ALT), $2368 \mathrm{U} / \mathrm{L}$; aspartate aminotransferase (AST), $1996 \mathrm{U} / \mathrm{L}$; prothrombin time/international normalized ratio (PT/INR), 47\%/1.51; total bilirubin, $21.80 \mathrm{mg} /$ $\mathrm{dL}$; direct bilirubin, $12.10 \mathrm{mg} / \mathrm{dL}$ (Table 1). The patient stated that she had taken one tablet per day of the herbal product Epinerve (SIFI, Catania, Italy), which is made from a dry aqueous extract of green tea containing $90 \%$ of EGCG, for 1 month. The herbal product had been prescribed by her ophthalmologist to treat glaucoma. The patient had also been taking simvastatin $20 \mathrm{mg}$ one tablet/ day; butizide + kalium canrenoate, one tablet on alternate days, for several years; travoprost eye drops, one drop/eye twice a day, for 2 years. The herbal supplement was stopped, and the patient's clinical condition improved. After 3 months of follow-up the patient completely recovered.

According to RUCAM, the liver injury has been classified as "hepatocellular". The RUCAM score was 4, so the relationship is "possible".

Case 2

A 72-year-old Italian woman was admitted to the hospital with symptoms of acute jaundice. Laboratory tests showed high values of bilirubin (total bilirubin $18 \mathrm{mg} / \mathrm{dL}$ ), of the cholestasis index, and of transaminases (AST and ALT > $700 \mathrm{U} / \mathrm{L})$ (Table 1). Serologic and virologic markers for hepatic viruses were all negative. Blood samples were negative for antibodies against cytomegalovirus and Epstein-Barr virus. Autoantibodies anti-nucleus, anti-mitochondrion, and anti-smooth muscle results were negative. Values of $\alpha 1$-antitrypsin and ceruloplasmin were in the normal range. The results from abdominal echography and magnetic resonance imaging of biliary ways excluded an 
obstruction of the biliary tract. A hepatic biopsy identified a cholestatic hepatitis and a granulomatous cholangitis.

The medical history of the patient at admission did not reveal risk factors for hepatitis; it only revealed a weak hypertension that did not require pharmacological treatment. The woman mentioned that she had been taking two dietary supplements: Epinerve (SIFI, Catania, Italy) two tablets/day and Luteinofta (SOOFT, Montegiorgio, Ascoli Piceno, Italy) one tablet/day, for 3 months. The products were prescribed by an ophthalmologist to treat glaucoma. Luteinofta contains lutein $10 \mathrm{mg} /$ tablet and vitamin E $12 \mathrm{mg} /$ tablet; the composition of Epinerve has been described above.

During hospitalization, the patient was treated with ursodesossicholic acid $10 \mathrm{mg} / \mathrm{kg}$ and glutathione (GSH) intravenously; the levels of liver enzymes progressively decreased, and they were in the normal range at discharge. At the 1-year follow-up, the parameters were unchanged.

According to RUCAM, the liver injury has been classified as "hepatocellular". The RUCAM score was 5, so the relationship is "possible".

\section{Discussion}

Tea is the most consumed beverage in the world, aside from water. Green tea has gained attention of both consumers and researchers in the last few years for its potential health benefits. Because of its wide-spread and long use, it is considered to be safe. Nevertheless, several cases of hepatotoxicity following the consumption of dietary supplements containing green tea have been reported.

In few of the cases reviewed here, the hepatotoxic reaction may have been related to concomitant medications, i.e. when green tea was associated with diclofenac [12] or paracetamol $[11,20]$, since hepatotoxicity has been reported for these drugs [36-38]. Three other patients were also taking progestogens [13, 14, 33], which has been associated with some cases of toxic hepatitis [39, 40]. In the fatal case [25], the product was adulterated with $n$ nitrosofenfluramine, an analog of fenfluramine with hepatotoxic effects that has also been found in other slimming products [41]. With the exception of these seven cases, the other 27 cases $(80 \%)$ accredited green tea as the main cause for the hepatic damage. In fact, the reported hepatotoxic reactions showed a temporal relationship between the consumption of green tea preparations and the onset of the effects: $70 \%$ of the patients had been taking green tea for a period of between 1 week and 3 months, and this time period can be considered to be "suggestive" in the causality assessment according to RUCAM. The dechallenge was always positive. Risk factors and non-drugrelated causes were generally excluded. Furthermore, in seven cases the rechallenge was positive. In our view, the published evidence from case reports suggests a causal association between green tea and hepatotoxicity. The most convincing finding is represented by the seven cases $(20 \%)$ of positive rechallenge.

In the two new cases here reported the correlation between green tea consumption and hepatotoxicity was assessed to be "possible" according to the RUCAM score. In both cases, the time of onset of the reaction was correlated to herbal drug exposure, the dechallenge was positive, the rechallenge was not performed, and age represented a risk factor. Unfortunately, non-drug-related causes (viral infections, alcoholism, etc.) can not be excluded in the first case, owing to a lack of detailed information. In the second case, non-drug-related causes can be excluded according to clinical pathology. The patient, however, had been taking a concomitant product (Luteinofta) with a compatible time of onset of the reaction, even if no hepatotoxicity has been reported for this supplement. This fact has been taken into account in the causality assessment and affected the RUCAM score.

With regard to the green tea chemical components responsible for the observed adverse reactions, it has to be noted that the tea preparations used were powdered leaves, infusions, and extracts (both aqueous and hydroalcoholic) and mostly contained standard levels of polyphenols (20-97\%). These preparations differ from one another in composition: powdered leaves contain all of the tea chemical components, infusions and aqueous extracts contain mostly hydrophilic compounds, while hydroalcoholic extracts contain both hydrophilic and lipophilic components. A possible hepatotoxicity due to lipophilic components was excluded by Bun et al. on the basis of results obtained from in vivo experiments [42]. Catechins are polar substances that are soluble both in water and hydro-alcoholic vehicles, so they are contained both in aqueous and in hydro-alcoholic extracts even if their content is higher in the latter [42]. Therefore, the components responsible for hepatotoxicity are probably catechins and their gallic acid esters, particularly EGCG.

To explain how green tea catechins can induce liver injury, a number of points have to be taken into account:

1. Pharmacological, particularly pharmacokinetic, interactions between green tea components and concomitant drugs can be hypothesized, as in the cases described above that were possibly related to concomitant medications. However, green tea components seem to affect cytochrome P450 (CYP1A2, CYP2D6, CYP2C9, and CYP3A4) activity either only slightly or not at all [43, 44]. Moreover, in four of the seven cases with positive rechallenge, no concomitant medications were reported.

2. Most of the case reports of green tea hepatotoxicity involved women. Even though we must take into 
account that women are the main users of herbal products, particularly those for body weight control, host genetic factors could be important in modulating susceptibility to green tea, as suggested by JimenezSaenz and Martinez-Sanchez [45]. In this context, Goodin et al. found that in Swiss Webster mice, females are more susceptible than males to EGCGmediated toxicity [46].

3. The bioavailability of catechins after oral administration is low: EGCG levels detected in plasma correspond to $0.2-2.0 \%$ of the ingested amount [47]; however, catechin plasma levels can increase under particular conditions. Isbrucker et al. found that the plasma area under the curve (AUC) for EGCG was significantly higher in fasted (205.7 $\mathrm{ng} \mathrm{h} / \mathrm{mL})$ than in pre-fed dogs (19.8 ng h/mL) after 2 weeks dosing at $300 \mathrm{mg} / \mathrm{kg}$ per day by dietary administration [48]. The same authors did not observe adverse effects when $500 \mathrm{mg} / \mathrm{kg}$ per day EGCG were administered for 13 weeks to pre-fed dogs; conversely, this dose caused morbidity when administered to fasted dogs [48]. Other studies in healthy volunteers showed that after the administration of $800 \mathrm{mg}$ Polyphenon E, a decaffeinated extract of green tea containing $60 \%$ EGCG, the plasma $\mathrm{C}_{\max }$ of free EGCG in the fasting condition was more then fivefold higher than that obtained after administration of the same dose with food [49]. Finally, Ullman et al. showed that after repeated administrations of EGCG $800 \mathrm{mg} /$ day, the $\mathrm{C}_{\max }$ was $1682 \mathrm{ng} / \mathrm{mL}$ on day 1 and $2431 \mathrm{ng} / \mathrm{mL}$ on day 10 [50].

4. Significant uptake of EGCG by the liver has been shown under conditions intended to simulate chronic administration [51].

5. High doses of green tea extracts and catechins show toxicity after oral administration. In rats, the dietary administration of $500 \mathrm{mg} / \mathrm{kg}$ per day EGCG for 13 weeks increased bilirubin and decreased fibrinogen, while a single dose of $2000 \mathrm{mg} / \mathrm{kg}$ EGCG by the oral route was toxic [48]. The dietary administration of a green tea extract containing 55.3\% catechins to rats for 90 days increased ALT, AST, and ALP levels and the liver weight at the maximum tested dose of about $3500 \mathrm{mg} / \mathrm{kg}$ [52]. Conversely, after intraperitoneal administration, low doses $(50 \mathrm{mg} / \mathrm{kg})$ of EGCG induced severe hepatic necrosis and a $20 \%$ mortality rate in mice [46]; in rats, $100 \mathrm{mg} / \mathrm{kg}$ EGCG induced an increase in plasma ALT levels, and $150 \mathrm{mg} / \mathrm{kg}$ caused the death of the animals in less than $24 \mathrm{~h}$ [53].

6. Although most of the potential health benefits of green tea and tea catechins have been attributed to their antioxidant properties, an increasing body of evidence suggests that polyphenols can behave as pro-oxidative agents. Experiments performed in rat liver cells showed that high concentrations of green tea extracts and of single tea phenolics are toxic; this cytotoxicity appears to be related to the gallic acid unit, and the most toxic compound was EGCG, while the least cytotoxic one was epicatechin (EC) [53, 54]. Cytotoxicity was associated with reactive oxygen species formation and depletion of GSH; GSH-depleted hepatocytes were more susceptible to EGCG cytotoxicity and ROS formation, suggesting that GSH plays a role in detoxifying this compound [53]. (-)-Epigallocatechin gallate cytotoxicity and ROS formation increased significantly by dicumarol, a NAD(P) $\mathrm{H}$ :quinone oxidoreductase 1 (NQO1) inhibitor, thus suggesting that $o$-quinone metabolites of EGCG cause cytotoxicity and are reductively detoxified by NQO1 [53]. Treatment with the catechol-O-methyltranferase inhibitor, entacapone, was also found to cause a significant increase in EGCG cytotoxicity and ROS formation, thus suggesting that hepatocyte methylation plays a role in detoxifying this compound [53]. According to Sang et al., catehol-O-methyltranferase can protect cells from EGCG-mediated oxidative stress and hepatotoxicity by methylation at the 4'- and 4"-hydroxyl groups, both of which are possible sites for quinone formation and redox cycling [55]. (-)-Epigallocatechin gallate has also been shown to induce oxidative stress in vivo. Sang et al. demonstrated that toxic doses of EGCG [200 and $400 \mathrm{mg} / \mathrm{kg}$ intraperitoneal (ip)] resulted in the formation of two cysteine conjugates of EGCG (EGCG2 '-cysteine and EGCG-2"-cysteine) and proposed that these conjugates arise from the formation of an EGCG quinone, which then reacts with the sulphydryl group on cysteine and likely with other cysteine-containing molecules such as GSH [56]. Moreover, treatment of lung tumor-bearing nude mice with daily injections of $40 \mathrm{mg} / \mathrm{kg}$ ip EGCG for 40 days resulted in increased expression of phosphorylated histone 2AX (a marker of DNA damage) and metallothionein (a marker of response to oxidative stress) in the liver and tumors relative to vehicle-treated mice [57].

On the basis of these results, we can conclude that the suspected hepatic reactions from green tea canlikely be ascribed to catechins, particularly to EGCG. The bioavailability of catechins is low after oral administration; however, under specific conditions, such as fasting, and after repeated administration, catechin plasma levels can rise and reach toxic levels. The hepatotoxicity can be imputed to the capability of EGCG or its metabolites to induce oxidative stress in the liver. Furthermore, taking into account that most of the reported liver injuries involve women, a gender susceptibility to green tea hepatotoxicity may be hypothesized. In some cases, an 
idiosyncratic or an immune-allergic mechanism can not be excluded.

Green tea preparations are widely used for their supposed health benefits. Their efficacy has not been proved; conversely, their use is associated with adverse events, particularly with hepatotoxic reactions. A green teabased product was withdrawn from the market after several hepatic reactions, but others are being continually introduced. Since these preparations are marketed as dietary supplements, they are generally used as self medication, i.e. beyond medical control, which increases the risk of adverse events. For all of these reasons, it appears necessary to provide detailed information to the users and to improve the active surveillance of these products.

\section{References}

1. Bruneton J (1999) Pharmacognosy, phytochemistry, medicinal plants, 2nd edn. Lavoisier Publ, Paris

2. Dufresne CJ, Farnworth ER (2001) A review of latest research findings on the health promotion properties of tea. J Nutr Biochem $12: 404-421$

3. Wolfram S (2007) Effects of green tea and EGCG on cardiovascular and metabolic health. J Am Coll Nutr 26:373S-388S

4. Shula Y (2007) Tea and cancer chemoprevention: a comprehensive review. Asian Pac J Cancer Prev 8:155-166

5. Kao YH, Chang HH, Lee MJ, Chen CL (2006) Tea, obesity, and diabetes. Mol Nutr Food Res 50:188-210

6. Menniti-Ippolito F, Mazzanti G, Santuccio C et al (2008) Surveillance of suspected adverse reactions to natural health products in Italy. Pharmacoepidemiol Drug Saf 17:626-635

7. Ben Yahia M, Mavier P, Metreau JM et al (1993) Chronic active hepatitis and cirrhosis induced by wild germander. Three cases. Gastroenterol Clin Biol 17:959-962

8. Castot A, Larrey D (1992) Hepatitis observed during a treatment with a drug or tea containing Wild Germander. Evaluation of 26 cases reported to the Regional Centers of Pharmacovigilance. Gastroenterol Clin Biol 16:916-922

9. Legoux JL, Maitre F, Labarriere D, Gargot D, Festin D, Causse X (1992) Cytolytic hepatitis and wild germander: a new case with reintroduction. Gastroenterol Clin Biol 16:813-815

10. Danan G, Benichou C (1993) Causality assessment of adverse reactions to drugs-I. A novel method based on the conclusions of international consensus meetings: application to drug-induced liver injuries. J Clin Epidemiol 46:1323-1330

11. Shim M, Saab S (2008) Severe hepatotoxicity due to Hydroxycut: a case report. Dig Dis Sci. doi:10.1007/s10620-008-0353-4

12. Bjornsson E, Olsson R (2007) Serious adverse liver reactions associated with herbal weight-loss supplements. J Hepatol 47:295-297 author reply 297-298

13. Federico A, Tiso A, Loguercio C (2007) A case of hepatotoxicity caused by green tea. Free Radic Biol Med 43:474

14. Molinari M, Watt KD, Kruszyna T et al (2006) Acute liver failure induced by green tea extracts: case report and review of the literature. Liver Transpl 12:1892-1895

15. Javaid A, Bonkovsky HL (2006) Hepatotoxicity due to extracts of Chinese green tea (Camellia sinensis): a growing concern. J Hepatol 45:334-335 author reply 335-336

16. Martinez-Sierra C, Rendon Unceta P, Martin Herrera L (2006) Acute hepatitis after green tea ingestion. Med Clin (Barc) 127:119
17. Jimemez-Saenz M, Martinez-Sanchez C (2006) Acute hepatitis associated with the use of green tea infusions. J Hepatol 44:616-617

18. Bonkovsky HL (2006) Hepatotoxicity associated with supplements containing Chinese green tea (Camellia sinensis). Ann Intern Med 144:68-71 Erratum in: Ann Intern Med 144:380

19. Mathieu N, Bouallegue L, Mognol P, Vallot T, Soule JC (2005) Hepatic toxicity probably due to X-elles used in phytotherapy. Gastroenterol Clin Biol 29:1188-1189

20. Gloro R, Hourmand-Ollivier I, Mosquet B et al (2005) Fulminant hepatitis during self-medication with hydroalcoholic extract of green tea. Eur J Gastroenterol Hepatol 17:1135-1137

21. Abu el Wafa Y, Benavente Fernandez A, Talavera Fabuel A, Perez Ramos MA, Ramos-Clemente JI (2005) Acute hepatitis induced by Camellia sinensis (green tea). An Med Interna 22:298

22. Stevens T, Qadri A, Zein NN (2005) Two patients with acute liver injury associated with use of the herbal weight-loss supplement hydroxycut. Ann Intern Med 142:477-478

23. Porcel JM, Beilsa S, Madroñero AB (2005) Hepatotoxicity associated with green tea extracts (electronic letters). Available online at http://www.annals.org/cgi/eletters/142/6/477\#1669

24. Garcia-Moran S, Saez-Royuela F, Gento E, Lopez Morante A, Arias L (2004) Acute hepatitis associated with Camellia tea and Orthosiphon stamineus ingestion. Gastroenterol Hepatol 27:559560

25. Lau G, Lo DS, Yao YJ, Leong HT, Chan CL, Chu SS (2004) A fatal case of hepatic failure possibly induced by nitrosofenfluramine: a case report. Med Sci Law 44:252-263

26. Dueñas Sadornil C, Fabregas Puigtio S, Durandez R (2004) Hepatotoxicity due to Camelia sinensis. Med Clin (Barc) 122:677-678

27. Peyrin-Biroulet L, Petitpain N, Kalt P et al (2004) Probable hepatoxicity from epigallocatecol gallate used for phytotherapy. Gastroenterol Clin Biol 28:404-406

28. Vial T, Bernard G, Lewden B, Dumortier J, Descotes J (2003) Acute hepatitis due to Exolise, a Camellia sinensis-derived drug. Gastroenterol Clin Biol 27:1166-1167

29. Pedros C, Cereza G, Garcia N, Laporte JR (2003) Liver toxicity of Camellia sinensis dried etanolic extract. Med Clin (Barc) 121:598-599

30. Bajaj J, Knox JF, Komorowski R, Saeian K (2003) The irony of herbal hepatitis: Ma-Huang-induced hepatotoxicity associated with compound heterozygosity for hereditary hemochromatosis. Dig Dis Sci 48:1925-1928

31. Kanda T, Yokosuka O, Tada $\mathrm{M}$ et al (2003a) $N$-nitrosofenfluramine hepatotoxicity resembling chronic hepatitis. J Gastroenterol Hepatol 18:999-1000

32. Kanda T, Yokosuka O, Okada O, Suzuki Y, Saisho H (2003b) Severe hepatotoxicity associated with Chinese diet product 'Onshidou-Genbi-Kounou'. J Gastroenterol Hepatol 18:354355

33. Thiolet C, Mennecier D, Bredin C et al (2002) Acute cytolysis induced by Chinese tea. Gastroenterol Clin Biol 26:939-940

34. Seddik M, Lucidarme D, Creusy C, Filoche B (2001) Is Exolise hepatotoxic? Gastroenterol Clin Biol 25:834-835

35. Gavilan JC, Bermudez FJ, Salgado F, Pena D (1999) Phytotherapy and hepatitis. Rev Clin Esp 199:693-694

36. Aithal GP, Day CP (2007) Nonsteroidal anti-inflammatory druginduced hepatotoxicity. Clin Liver Dis 11:563-575

37. Gomez-Lechon MJ, Ponsoda X, O’Connor E, Donato T, Jover R, Castell JV (2003) Diclofenac induces apoptosis in hepatocytes. Toxicol In Vitro 17:675-680

38. Larson AM (2007) Acetaminophen hepatotoxicity. Clin Liver Dis 11:525-548

39. Magnin G, de Meeus JB, Sarfati R, Chaouchi O, Paillat A (1996) Hepatic cytolysis caused by tocolytic treatment using micronized natural progesterone. Presse Med 25:102-105 
40. Altintas E, Oguz D, Kacar S, Ozderin Y, Sezgin O, Zengin NI (2004) Dydrogesterone-induced hepatitis and autoimmune haemolytic anemia. Turk J Gastroenterol 15:49-52

41. Yuen YP, Lai CK, Poon WT, Ng SW, Chan AY, Mak TW (2007) Adulteration of over-the-counter slimming products with pharmaceutical analogue - an emerging threat. Hong Kong Med J 13:216-220

42. Bun SS, Bun H, Guédon D, Rosier C, Ollivier E (2006) Effect of green tea extracts on liver functions in Wistar rats. Food Chem Toxicol 44:1108-1113

43. Chow HH, Hakim IA, Vining DR et al (2006) Effects of repeated green tea catechin administration on human cytochrome P450 activity. Cancer Epidemiol Biomarkers Prev 15:2473-2476

44. Donovan JL, Chavin KD, Devane CL et al (2004) Green tea (Camellia sinensis) extract does not alter cytochrome P450 3A4 or 2D6 activity in healty volunteers. Drug Metab Dispos 32:906-908

45. Jimenez-Saenz M, Martinez-Sanchez C (2007) Green tea extracts and acute liver failure: the need for caution in their use and diagnostic assessment. Liver Transpl 13:1067

46. Goodin MG, Bray BJ, Rosengreen RJ (2006) Sex- and straindependent effects of epigallocatechin gallate (EGCG) and epicatechin gallate (ECG) in the mouse. Food Chem Toxicol 44:1496-1504

47. Nakagawa K, Okuda S, Miyazawa T (1997) Dose-dependent incorporation of tea catechins, (-)-epigallocatechin-3-gallate and (-)epigallocatechin into human plasma. Biosci Biotechnol Biochem 61:1981-1985

48. Isbruker RA, Edwards JA, Wolz E, Davidovich A, Bausch J (2006) Safety studies on epigallocatechin gallate (EGCG) preparations. Part 2: dermal, acute and short-term toxicity studies. Food Chem Toxicol 44:636-650
49. Chow HH, Hakim IA, Vining DR et al (2005) Effects of dosing condition on the oral bioavailability of green tea catechins after single-dose administration of Polyphenon E in healthy individuals. Clin Cancer Res 11:4627-4633

50. Ullmann U, Haller J, Decourt JP et al (2003) A single ascending dose study of epigallocatechin gallate in healthy volunteers. J Int Med Res 31:88-101

51. Lambert JD, Lee MJ, Lu H et al (2003) Epigallocatechin-3-gallate is absorbed but extensively glucuronidated following oral administration to mice. J Nutr 133:4172-4177

52. Takami S, Imai T, Hasumura M, Cho YM, Onose J, Hirose M (2008) Evaluation of toxicity of green tea catechins with 90-day dietary administration to F344 rats. Food Chem Toxicol 46:22242229

53. Galati G, Lin A, Sultan AM, O'Brien PJ (2006) Cellular and in vivo hepatotoxicity caused by green tea phenolic acids and catechins. Free Radic Biol Med 40:570-580

54. Schmidt M, Schmitz HJ, Baumgart A et al (2005) Toxicity of green tea extracts and their constituents in rat hepatocytes in primary culture. Food Chem Toxicol 43:307-314

55. Sang S, Hou Z, Lambert JD, Yang CS (2005) Redox properties of tea polyphenols and related biological activities. Antioxid Redox Signal 7:1704-1714

56. Sang S, Lambert JD, Hong J et al (2005) Synthesis and structure identification of thiol conjugates of (-)-epigallocatechin gallate and their urinary levels in mice. Chem Res Toxicol 18:17621769

57. Lambert JD, Sang S, Yang CS (2007) Possible controversy over dietary polyphenols: benefits vs risks. Chem Res Toxicol 20:583585 